\title{
A Validation of the Ultrasound Wave Velocity Method to Predict Porosity of Dry and Saturated Cement Paste
}

\author{
Zhenting Zou (iD) ${ }^{1}$ and Jay N. Meegoda ${ }^{2}$ \\ ${ }^{1}$ Dynamic Engineering Consultants PC, Chester, NJ 07930, USA \\ ${ }^{2}$ Civil and Environmental Engineering, New Jersey Institute of Technology, Newark, NJ 07102, USA \\ Correspondence should be addressed to Zhenting Zou; zz85@njit.edu
}

Received 15 August 2017; Accepted 5 March 2018; Published 5 April 2018

Academic Editor: Arnaud Perrot

Copyright ( $) 2018$ Zhenting Zou and Jay N. Meegoda. This is an open access article distributed under the Creative Commons Attribution License, which permits unrestricted use, distribution, and reproduction in any medium, provided the original work is properly cited.

\begin{abstract}
An approximate theoretical validation of the measured variation of ultrasound velocity with porosity of dry and saturated cement paste is proposed using finite element analysis of cement paste assuming as a multiphase composite. Cement paste is a multiphase composite consisting of solid cement and microscopic voids filled either with air or water. The void content in cement paste is directly related to strength and durability. Experimental tests showed that ultrasound wave velocity is decreased with the increase in porosity of cement paste, where pore sizes are similar in dimension to the wavelength of the sound enabling ultrasound to be used as a potential condition assessment technique. However, the variation of ultrasound wave velocity also depends on the fluid in the voids. Several finite element simulations using two commercially available software packages were performed for both fully saturated and dry blocks of cement paste with different porosities. Then back-calculated elastic moduli values from finite element simulations were used to compute the wave velocities of both fully saturated and dry cement paste with different porosities. The predicted ultrasound velocities with porosity for both dry and saturated cement paste are compared well with the laboratory measurements.
\end{abstract}

\section{Introduction}

Cement is counted among the key building materials both in the residential and nonresidential sectors. It was estimated that the global market was sized at around 395 billion U.S. dollars in 2016 [1]. Concrete is a cement-based building material which is critical worldwide, with over 500 million tons of annual production in the USA [2]. Unfortunately, various environmental factors affect cement-based materials, causing degradation, namely, aging, chemical and physical damage, freezing/thawing, fire, and corrosion of reinforcement $[3,4]$. The durability and integrity of concrete are affected by cement paste because concrete is made of a matrix of cement mortar and aggregate. Hydrated and hardened cement paste is fluidfilled pores and an interconnected network of solid grains [5]. Hydrated cement paste properties such as strength, durability, shrinkage, and fracture behavior are affected by paste composition and structure [6]. It is well known that aggressive agents such as salt water will move through interconnected pores leading to degradation of concrete. Resistance to penetrating agents is widely recognized as an indicator of the durability of cementitious material [7]. Thus, cement paste porosity is a key structural property that needs to be quantified by performing in situ tests.

Currently, destructive and nondestructive in situ tests are used in estimating voids in concrete. Destructive tests require specimens to be removed from the structures to evaluate structural performance. This is not preferable as such tests may damage the structure. Nondestructive tests (NDT) and partial destructive tests, which do no damage or slightly damage the structure, are wildly used to evaluate the concrete performance. Nondestructive test using ultrasound is a common method to evaluate the performance of concrete structures.

Ultrasound techniques that detect defects, which measure the mechanical properties, or monitor the state of deterioration of concrete have been a topic of considerable 
interest to the civil infrastructure community $[8,9]$. Nondestructive test using ultrasound is a common method to evaluate the performance of concrete structures, where the velocity of the ultrasound is the most widely used parameter for characterization. Low frequency $(20-40 \mathrm{kHz})$ ultrasound is also used for leak detection [10] and for sediment decontamination [11].

Jones [12] proposed the use of ultrasound velocity measurements for nondestructive evaluation of Portland cement concrete. The ultrasound velocity method applies ultrasound to the test structure, and the wave propagates through the material and is received by the receiver. By analyzing the received signal, the condition of the material can be evaluated. The ultrasound pulse velocity is by far the most widely accepted method for assessing the quality of concrete in structures [13]. In addition, the frequency domain analysis can provide significant additional information $[13,14]$. Elastic waves are directly related to the elastic properties of the porous material. Hence, ultrasound velocities can be used to estimate mechanical properties such as modulus of cement. When the ultrasound propagates in a homogeneous, linearly elastic material, the compression and shear wave velocity are related to the media's elastic moduli by the following expressions:

$$
\begin{aligned}
& V_{\mathrm{L}}=\sqrt{\frac{E(1-v)}{\rho(1+v)(1-2 v)}}=\sqrt{\frac{K+(4 / 3) G}{\rho}}, \\
& V_{\mathrm{T}}=\sqrt{\frac{E}{2 \rho(1+v)}}=\sqrt{\frac{G}{\rho}},
\end{aligned}
$$

where $V_{\mathrm{L}}$ is the compression wave velocity, $V_{\mathrm{T}}$ is the shear wave velocity, $E$ is Young's modulus, $v$ is Poisson's ratio, and $\rho$ is the density. These expressions clearly show the impact on ultrasound velocity of elastic properties of cement.

Since for porous material elastic moduli is a function of porosity $[15,16]$, ultrasound velocity in homogeneous material would depend on porosity. When an ultrasound wave propagates through a material, the wave velocity is related to its density and the elastic modulus [17] and the elastic tensor depends on porosity.

Over the last past decades, extensive research has being performed for the development of efficient and reliable methods to identify defects [18]. For instance, ultrasound velocity is the most common NDT method used for material characterization.

Cement paste forms the matrix phase of mortar and concrete; in order to fully understand the behavior of mortar and concrete, the first step would be to understand the performance of cement paste. Many researchers have investigated performance of cement paste by assuming the cement paste as a two-phase homogeneous nonporous paste with pores. Maalej et al. [19] used different water/cement ratios to create specimens with varying porosity values. Then broadband ultrasound spectroscopy [20] was used to induce ultrasound wave transmission into the materials with a single transducer. Ultrasound with $1 \mathrm{MHz}$ frequency was applied to the sample. To transfer sufficient energy to the

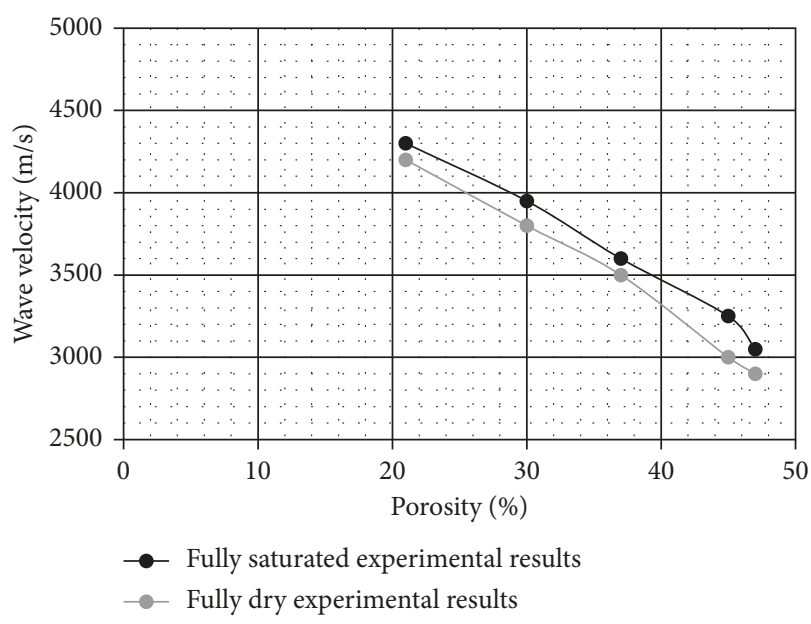

Figure 1: Experimental data of fully saturated and fully dry wave velocity with porosity [19].

sample, typically, adequate coupling should be applied. However, to avoid water penetration into the sample during the test, direct contact was chosen instead of immersion coupling. The single transducer was used as both transmitter and receiver. The time to receive two signals $s 1(t)$ which is the signal reflected from the top of the sample and $s 2(t)$ which is the signal reflected from the bottom of the sample was read. Then, pulse velocity was obtained using the following equation:

$$
V_{\mathrm{L}}=\frac{2 e}{\Delta t},
$$

where $e$ is the thickness of the sample and $\Delta t$ is the time delay between signals $s 1(t)$ and $s 2(t)$. Experimental tests showed that the ultrasound wave velocity of saturated concrete of given porosity is higher than that of dry concrete. The results also show that the contribution of moisture saturation on the ultrasound wave velocity was significant. Maalej [21] prepared five samples with varying cement to water ratios 0 . To achieve workability of the cement paste, $1 \%$ of superplasticizer adjuvant was added to the cement by weight. During the first 48 hours, the samples were kept in the watertight environment. Then, the samples were stored in a $\mathrm{Ca}(\mathrm{OH})_{2}$ solution at constant temperature for another 28 days. The samples stored in the lime solution were considered fully saturated. For dry samples, they were oven dried at $60^{\circ} \mathrm{C}$. Samples were taken out for test when they had constant weight. Maalej et al. [19] showed that the ultrasound wave velocity decreased with the increase in porosity of cement paste (Figure 1).

Maalej et al. [19] also compared the above experiment results to predictions from four theoretical micromechanical models. All micromechanical models could not accurately predict the experimented results especially when the voids were filled with air or water. Because of this, this research attempts to provide an approximate theoretical basis for the measured variation of ultrasound velocity with porosity of dry and saturated cement paste using the finite element method (FEM). 
TABle 1: Cement paste elastic moduli at zero porosity [19].

\begin{tabular}{lcccc}
\hline & \multicolumn{2}{c}{ Cement paste at zero porosity } & \multicolumn{2}{c}{ Pores } \\
& Bulk $(\mathrm{MPa})$ & Shear $(\mathrm{MPa})$ & Bulk $(\mathrm{MPa})$ & Shear $(\mathrm{MPa})$ \\
\hline Dry & 30,182 & 17,662 & 0 & 0 \\
Saturated & 33,919 & 17,884 & 2,200 & 0 \\
\hline
\end{tabular}

TABle 2: Densities of dry and saturated phases [19].

\begin{tabular}{lcc}
\hline & Dry $\left(\mathrm{kg} / \mathrm{m}^{3}\right)$ & Saturated $\left(\mathrm{kg} / \mathrm{m}^{3}\right)$ \\
\hline Cement paste at & 2,579 & 2,579 \\
zero porosity & 1.204 & 1,000 \\
Pores &
\end{tabular}

\section{Finite Element Method Model Setup}

The finite element method (FEM) is a numerical method for predicting how an object reacts to real-world forces and energy. It does not yield an exact solution but rather an approximation to the exact solution. Since the late 1960s, the finite element method has been used for a wide range of engineering problems. By using the FEM, the continuous physical problem can be solved to calculate the discretized nodal values. The FEM has been known to accurately calculate the elastic properties of objects [22] and was successful in estimating the elastic moduli of composite materials $[23,24]$. In this research, two commercially available software packages were used to simulate the elastic behavior of cement paste, where the elastic modulus of cement paste with different porosities was back-calculated. Ultrasound testing in concrete is mainly used to evaluate the performance of the material under compressive loads [25]. Hence, in this research, model simulations were performed subjected to compressive loads.

2.1. Simulation of the Model Geometry. Like most of the micromechanics models, cement paste was treated as twophase composite including nonporous cement and voids. Consequently, a solid cement block was proposed, and voids in the cement were idealized and concentrated together as inclusions inside solids. By adjusting the volume of inclusions, different porosity values of cement were simulated. Also by adjusting the material inside inclusions, dry and fully saturated situations were performed. Before the geometry is scoped, the material properties should be input to the program.

2.2. Void Shape. In micromechanical models, inclusion shape is usually ignored such as in bounding methods of Hashin [26], Hashin and Shtrikman [27], and Walpole [28] or by using specific shapes. It is convenient to have symmetrical inclusions such as ellipsoids, spheres, elliptical cylinders, circular cylinders, and penny- or needle-shaped ellipsoids. Consequently, symmetrical inclusions were used in this research. The orientation at the center of the cement block was related to the global coordinate system and symmetrically distributed inside the cement block.
2.3. Element Types and Boundary Condition. A 3D SOLID element was used to simulate the nonporous cement paste. A $3 \mathrm{D}$ and 8-node linear element with three degrees of freedom for each node-translation in the $X, Y$, and $Z$ directions was used. A hydrostatic fluid element (HSFLD242) was used to simulate the fluid inclusion such as void filled with fluids inside a solid model in order to modeling fluid-solid interaction with incompressible or compressible fluids under uniform pressure. It can be used in geometrically linear as well as nonlinear static and transient dynamic analyses [29]. When applying a vertical stress as a surface load on the top element face, it will be supported by the bottom face of the block; hence, there is no vertical displacement and zero rotation of the bottom surface. The remaining four sides will be free boundaries.

\section{FEM Simulation}

Two different commercially available FEM software packages were used in this research, where the second software package was used to compare and validate simulation results of porous cement paste filled with fluid.

3.1. FEM Simulations. For any FEM simulations, representative material properties are needed. The same material properties reported in Maalej et al. [19] were used since this study attempts to compare numerical simulations with experimental results. Their detailed experimental results of Maalej et al. [19] were presented in [30]. Soltani [30] obtained values of bulk and shear moduli for the cement paste at zero porosity from ultrasound velocity measurements and unit weight by using (1), and numerical values are listed in Table 1 . The density of pore fluids used in this simulation and the dense cement paste with no porosity are listed in Table 2 . The reported Young's modulus and Poisson's ratio of zero porosity cement paste were 44,337 MPa (9.26e8 psf) and 0.28, respectively, which correspond to a wave velocity of $4688 \mathrm{~m} / \mathrm{sec}(15381 \mathrm{ft} / \mathrm{sec})$ [19].

3.2. Back-Calculated Elastic Modulus. After performing the FEM simulations, the elastic modulus was back-calculated using the following equation:

$$
E=\frac{F * L_{0}}{A_{0} * \Delta L},
$$

where $E$ is Young's modulus, $F$ is the force exerted on an object under compression, here $0.34 \mathrm{MPa}(7200 \mathrm{psf}$ ) was used, $A_{0}$ is the actual cross-sectional area through which the force is applied, $\Delta L$ is the amount by which the length of the object changes, and $L_{0}$ is the original length of the object. After performing the FEM simulations, the elastic modulus was back-calculated by using (3). Please note that with an 
TABLE 3: Summarization of back-calculated Young's modulus and associated errors for different inclusion shapes.

\begin{tabular}{lccc}
\hline Inclusion shape & Porosity & Young's modulus from ANSYS & Error \\
\hline Sphere & $5 \%$ & $39,166 \mathrm{MPa}$ & \\
Circular cylinder & $5 \%$ & $38,399 \mathrm{MPa}$ & $2 \%$ \\
Ellipsoid with axial ratio of 1.3 & $5 \%$ & $40,267 \mathrm{MPa}$ & $3 \%$ \\
\hline
\end{tabular}

TABLE 4: Summarization of back-calculated Young's modulus and associated errors for different numbers and distributions of spheres.

\begin{tabular}{|c|c|c|c|c|c|c|}
\hline $\begin{array}{l}\text { Numbers and } \\
\text { distribution }\end{array}$ & 1 single sphere & $\begin{array}{l}2 \text { spheres, } \\
\text { random }\end{array}$ & $\begin{array}{l}2 \text { spheres, } \\
\text { vertical }\end{array}$ & $\begin{array}{l}2 \text { spheres, } \\
\text { horizontal }\end{array}$ & $\begin{array}{l}4 \text { spheres, } \\
\text { square }\end{array}$ & 4 spheres, star \\
\hline $\begin{array}{l}\text { Young's modulus } \\
(\mathrm{MPa})\end{array}$ & 37,059 & 36,819 & 38,112 & 35,718 & 37,969 & 37,115 \\
\hline Error & & $1 \%$ & $3 \%$ & $4 \%$ & $2 \%$ & $0 \%$ \\
\hline $\begin{array}{l}\text { Numbers and } \\
\text { distribution }\end{array}$ & $\begin{array}{l}8 \text { spheres, } \\
\text { vertical }\end{array}$ & $\begin{array}{l}8 \text { spheres, } \\
\text { horizontal }\end{array}$ & 9 spheres & $\begin{array}{l}10 \text { spheres, } \\
\text { horizontal }\end{array}$ & $\begin{array}{l}10 \text { spheres, } \\
\text { vertical }\end{array}$ & $\begin{array}{c}10 \text { spheres, varied } \\
\text { sizes }\end{array}$ \\
\hline $\begin{array}{l}\text { Young's modulus } \\
(\mathrm{MPa})\end{array}$ & 38,830 & 37,825 & 37,011 & 38,017 & 37,825 & 36,820 \\
\hline Error & $5 \%$ & $2 \%$ & $0 \%$ & $3 \%$ & $2 \%$ & $1 \%$ \\
\hline
\end{tabular}

inclusion or a void, the back-calculated Young's modulus would be lower than that of cement without voids.

3.3. Shape of Inclusions. As mentioned before, modeling geometry inclusions such as ellipsoids, spheres, elliptical cylinders, circular cylinders, or penny- or needle-shaped ellipsoids are often used in micromechanical models. Ellipsoidal inclusions can be characterized by the aspect ratio, which is the vertical axis over horizontal axis.

Maalej [21] showed five different aspect ratios:

$$
\begin{aligned}
& \alpha=1 \text { spherical inclusion } \\
& \alpha>1 \text { prolate spheroid (needle-shaped inclusion) } \\
& \alpha<1 \text { oblate spheroid (penny-shaped inclusion) } \\
& \alpha=0 \text { flat disk } \\
& \alpha=\infty \text { cylinder }
\end{aligned}
$$

The objective of this research was to compare the estimated wave velocity using simulation with the experimental data. In this research, circular cylinders and spheres were chosen as inclusions in the model. Since the cement paste is being considered as a two-phase material, voids distributed in the paste were represented a single equivalent inclusion or void at the center of the block. The size of the inclusion was adjusted to represent different void ratios of the paste. Then with different inclusion sizes, simulations were repeated with the same assigned material mesh and boundary conditions. Using the average displacements from simulation Young's modulus was calculated. For a certain porosity, different void shapes like sphere and circular cylinders can be calculated. With the same porosity of 5\%, Young's modulus of the model with the sphere shape inclusion was $39,116 \mathrm{MPa}$ (8.18e8 psf), that for the model with the ellipsoid shape inclusion was $40,267 \mathrm{MPa}(8.41 \mathrm{e} 8 \mathrm{psf})$, and that for the model with circular cylinders was $38,399 \mathrm{MPa}$ (8.02e $8 \mathrm{psf}$ ), with a maximum error of $5 \%$ with respect to spherical inclusion. Test results are listed in Table 3 . Based on simulation results, the shape of the inclusion had minimal impact on the back-calculated Young's modulus, so spherical voids were used in remaining simulations.

3.4. Number of Inclusions and Their Distribution. In the FEM simulation, an equivalent inclusion was used to represent the voids in the cement paste where voids in the cement paste are randomly distributed. Thus, it is necessary to evaluate the impact of the above assumption. Hence several simulations of block with inclusions distributed throughout the block were performed for given porosity, and the error between back-calculated modulus of single inclusion with inclusions distributed throughout the block was found to be insignificant. For a given porosity value of $10 \%$ several inclusions with varying distributions were simulated. Table 4 compares impact of number of equivalent inclusions and their distribution for a given void ratio showing a maximum error of $5 \%$.

3.5. Variation of Porosity. By adjusting the size of the sphere, the model can simulate different porosity values. Five different porosity values were simulated in this research. By using a given porosity value, the total volume of the void can be calculated, and therefore, the radius of sphere is calculated based on that volume. The simulation results and the back-calculated computed Young's modulus values presented in Figure 2 show that Young's modulus decreases with the increase of porosity.

3.6. Dry and Fully Saturated Inclusions. To test the changes in ultrasound velocity in dry or moisture-saturated cement paste, different fluid elements were assigned to the equivalent sphere in the FEM model to simulate air- and waterfilled voids. This was the most challenging aspect of this research, where the incorporation of fluid filled voids into elastic analysis without elastic modulus value for the fluid. For this purpose, the first FEM package represented the fully enclosed fluid using a special element called HSFLD242, and 


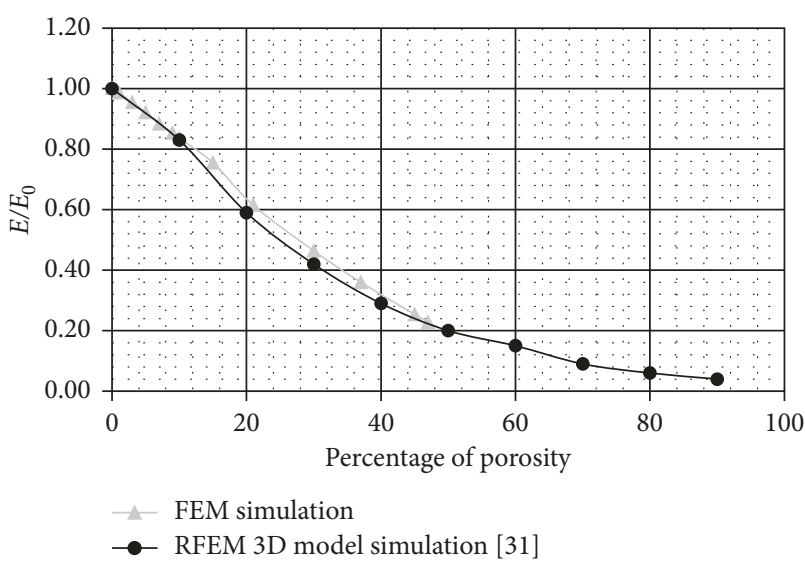

FIgURE 2: The variation of Young's modulus ratio with porosity.

the second FEM package represented the same using the concept called fluid cavity. When voids are filled with different fluids, the bulk modulus of the fluid would considerably impact the compressibility of the voids.

3.7. Simulation Results. In this research, it was attempted to simulate the porosity values reported in Maalej et al. [19] specifically $21 \%, 30 \%, 40 \%$, and $45 \%$. The void volume corresponding to above porosity values for one cubic foot volume was first computed. Then based on the above void volumes, radius of inclusion of the sphere at the center of the block was computed. After that, applying the zero-void elastic modulus of the cement paste was assigned to the block, and the material of the inclusion defined as air. The same process was used to generate mesh, and the previously defined boundary conditions were applied. By applying the vertical pressure on the top surface of the block, the enclosed fluid will expand and increase in fluid pressure inside the void. Consequently, the correct fluid pressure should be applied to the model. However, it is difficult to obtain a deformation versus pressure relationship for the inclusion. Please note that air is compressible and water is incompressible. As a result, the pressure inside the inclusion was assumed as equal to 1 standard atmosphere and the applied pressure of $0.34 \mathrm{MPa}$ (7200 psf), respectively, to air and water inclusion. First, the fluid element was assigned as air to simulate the dry condition. The initial pressure of the air in the sphere is one atmosphere, and after the boundary conditions were applied, the pressure inside the inclusion was assumed as one atmosphere. Then, the average displacement in $y$-axis was used to compute Young's modulus by using (3). However, to back-calculate the wave velocity, Poisson's ratio should be determined. Accordingly, the average lateral displacement values were used to calculate Poisson's ratio and the modified density based on the porosity. Finally, Equation (1) was used to obtain the longitude wave velocity. Then the radius was changed to simulate the different porosity values, and the above procedure was repeated. To simulate the fully saturated situation, a fluid element was used instead of air, and the above was repeated. But the pressure inside the inclusion is increased to applied

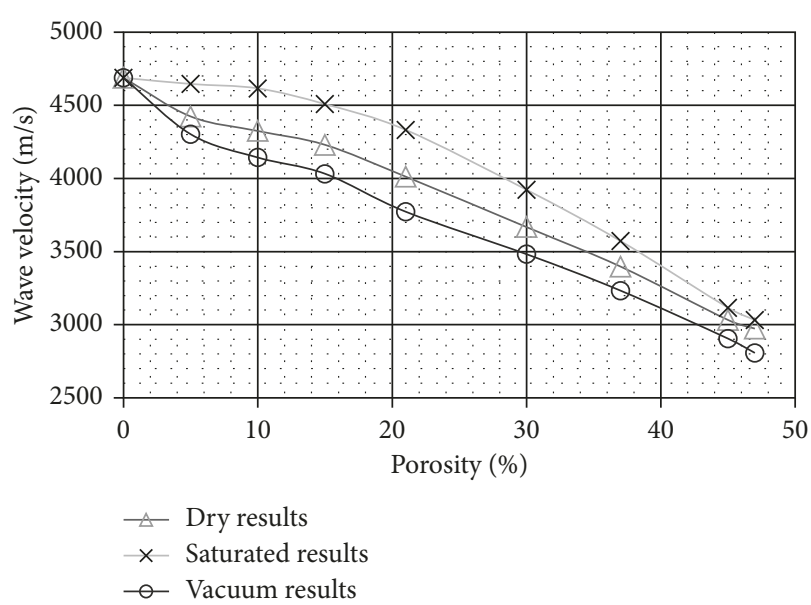

FIGURE 3: Variation of wave velocity with porosity based on fully saturated, fully dry, and vacuum results.

pressure of $0.34 \mathrm{MPa}$ (7200 psf). The FEM vacuum simulation which was reported in Figure 2 was extended and used to compare with the dry and saturated cement paste results. Figure 3 shows the simulation results.

\section{Discussion of Results}

The impact of the compressibility of the material in the inclusion for a given porosity, in vacuum, produced the lowest wave velocity followed by the dry void filled with air and then the void filled with incompressible water was shown in Figure 3. For example, when porosity value is equal to $21 \%$, wave velocities are $3775 \mathrm{~m} / \mathrm{sec}(12385 \mathrm{ft} / \mathrm{sec})$ for a vacuum inclusion with no compressibility of the inclusion, $4000 \mathrm{~m} / \mathrm{sec}(13123 \mathrm{ft} / \mathrm{sec})$ for an inclusion filled with partially compressible air, and $4325 \mathrm{~m} / \mathrm{sec}(14190 \mathrm{ft} / \mathrm{sec})$ for an incompressible inclusion filled with water. Compare those to a value of $4688 \mathrm{~m} / \mathrm{sec}(15380 \mathrm{ft} / \mathrm{sec})$ for no inclusion. The results are listed in Tables 5 and 6 .

The FEM simulation results show that the ultrasound velocity will decrease when the cement paste porosity is increased no matter whether it is dry or saturated. As mentioned before, ultrasound testing in concrete is mainly used to evaluate the quality of the material based on its porosity. Typically, larger porosity produces weaker cement. With higher porosity of concrete, aggressive fluids can enter concrete and leaching of calcium can occur, forming weaker material such as gypsum. Also, voids filled with fluid have much lower elastic modulus. The FEM simulation result also shows that, under the same applied vertical stress, there is higher deformation of the block with higher porosity, proving that the material becomes weaker when the porosity increases. From the simulation result, the ultrasound velocity will decrease with the increase in porosity because higher porosity means lower elastic modulus. Thus, the ultrasound method is a potentially powerful tool for the condition assessment of concrete. With degradation, the porosity is increased, causing the material to become weaker. On that account, ultrasound velocity via elastic modulus and the porosity can be used to estimate the condition state of structures. Maalej et al. [19] 
TABLE 5: Results for simulating different porosities under fully dry situation.

\begin{tabular}{|c|c|c|c|c|}
\hline \multicolumn{5}{|c|}{ Fully dry } \\
\hline Porosity (\%) & Young's modulus, $E(\mathrm{MPa})$ & Poisson's ratio & Density, $\rho\left(\mathrm{kg} / \mathrm{m}^{3}\right)$ & Velocity $(\mathrm{m} / \mathrm{s})$ \\
\hline 5 & 41,998 & 0.22 & 2450 & 4424 \\
\hline 10 & 38,020 & 0.22 & 2321 & 4324 \\
\hline 15 & 34,356 & 0.22 & 2192 & 4230 \\
\hline 21 & 28,739 & 0.22 & 2038 & 4013 \\
\hline 30 & 21,276 & 0.22 & 1806 & 3668 \\
\hline 37 & 16,433 & 0.22 & 1625 & 3398 \\
\hline 45 & 11,431 & 0.22 & 1419 & 3033 \\
\hline 47 & 10,590 & 0.22 & 1367 & 2973 \\
\hline
\end{tabular}

TABLE 6: Results for simulating different porosities under fully saturated situation.

\begin{tabular}{|c|c|c|c|c|}
\hline \multicolumn{5}{|c|}{ Fully saturated } \\
\hline Porosity (\%) & Young's modulus, E (MPa) & Poisson's ratio & Density, $\rho\left(\mathrm{kg} / \mathrm{m}^{3}\right)$ & Velocity $(\mathrm{m} / \mathrm{s})$ \\
\hline 5 & 42,213 & 0.28 & 2500 & 4646 \\
\hline 10 & 40,349 & 0.28 & 2421 & 4616 \\
\hline 15 & 37,236 & 0.28 & 2342 & 4508 \\
\hline 21 & 32,997 & 0.28 & 2247 & 4332 \\
\hline 30 & 25,340 & 0.28 & 2105 & 3923 \\
\hline 37 & 19,913 & 0.28 & 1995 & 3572 \\
\hline 45 & 14,193 & 0.28 & 1868 & 3116 \\
\hline 47 & 13,214 & 0.28 & 1837 & 3033 \\
\hline
\end{tabular}

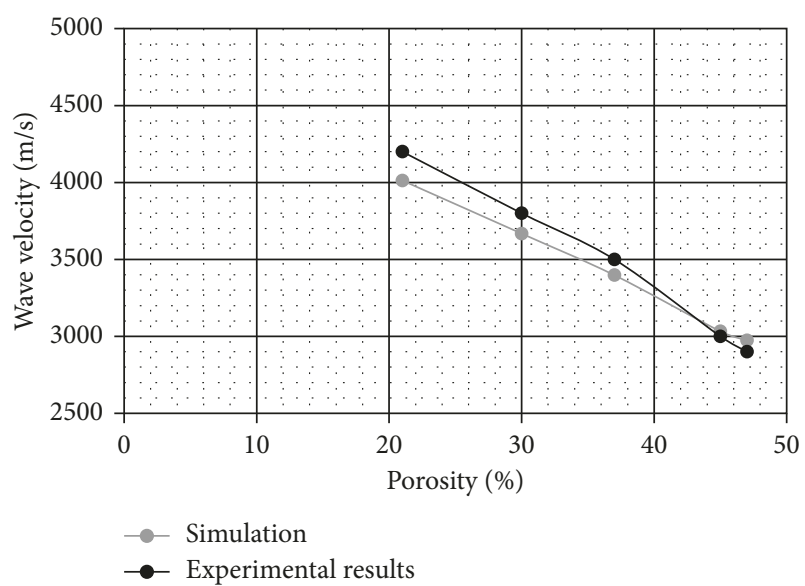

FIGURE 4: Comparison of back-calculated wave velocity of fully dry cement paste with those measured (experimental results of Maalej et al. [19]).

showed that the ultrasound wave velocity decreased with the increase in porosity of cement paste. However, there is no theoretical basis for the measured variation of ultrasound velocity with porosity of dry and saturated cement paste.

This study attempted to provide a theoretical explanation for the variation of ultrasound wave velocity with porosity for both dry and saturated cement paste using FEM simulations. In FEM simulations, the fluid is defined by the hydrostatic fluid element, which needs the bulk modulus of fluid. The bulk elastic properties of a material determine its elastic deformation and hence the wave propagation. With different bulk moduli, the compressibility values of the air and water voids are different. As a consequence, the deformation of void filled with air or water will be quite different. Cement paste

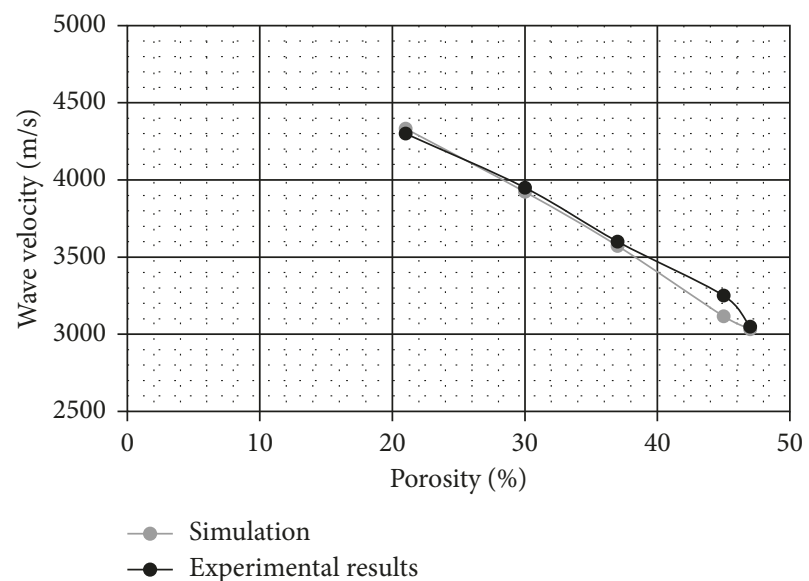

FIgURE 5: Comparison of back-calculated wave velocity of fully saturated cement paste with those measured (experimental results of Maalej et al. [19]).

filled with a water void is much harder to compress due to the higher bulk modulus of water, when compared with that of a void filled with air. Ultrasound testing of concrete is mainly used to evaluate the quality of the material, via its compressibility. Ergo, voids filled with different fluids will have different moduli due to the different enclosed fluids. As a result, the wave velocity of saturated cement paste is faster than that of dry cement paste at the same porosity due to the lower compressibility of water in the voids. This causes the elastic modulus of saturated cement paste to be higher than that of dry cement paste for the same porosity. Backcalculated, the wave velocity of saturated cement paste is faster than that of dry cement paste, as shown in Figures 4 and 5 that show comparison of measured results from Maalej et al. [19] 
and simulation results from this research confirming a good comparison. Figures 4 and 5 also provide a theoretical basis to validate the experimental results of Maalej et al. [19].

\section{Summary and Conclusions}

Nondestructive test using ultrasound is a common method to evaluate the performance of concrete structures, where the velocity of the ultrasound is the most wildly used parameter for characterization. Experimental tests show that the ultrasound wave velocity is decreased with the increase in porosity of cement paste. Hence ultrasound can be used as a potential condition assessment technique and also can be used to characterize the micromechanical structure. However, voids are filled with water and air provided separate ultrasound wave velocity variations. The FEM simulations using two commercially available software packages to provide an approximate theoretical validation of above experimental results were performed. The FEM simulation showed that void shape, number of void, and distribution of void do not have a major impact, and hence, the porous cement paste was idealized and simulated as one equivalent void at the center of a cube. The FEM simulation showed that under the fully saturated conditions the wave velocity is little faster than that under dry conditions. By comparing the simulated and back-calculated wave velocities with those measured for different porosities, this study attempted to provide a theoretical basis variation of ultrasound wave velocity with porosity for both dry and saturated cement paste. The simulated and back-calculated wave velocity values compared well with the laboratory measurements, confirming that the ultrasound velocity of dry and saturated cement paste is a function of elastic properties of cement, porosity, and compressibility of the voids.

\section{Conflicts of Interest}

The authors declare that they have no conflicts of interest.

\section{Acknowledgments}

Authors would like to acknowledge the contributions of Mr. Hadyn Ellis, the undergraduate student of Northwestern University, who worked as an undergraduate researcher at NJIT during summer of 2015, Dr. Shawn Chester of NJIT for helping with one software package especially with the fluidfilled cavities, technical staff of the other software package for numerous consultation on HSFLD242, and Dr. Zoubeir Lafhaj of Ecole Centrale de Lille, France, for introducing authors to the application of ultrasound technology for condition assessment of concrete.

\section{References}

[1] US Cement Industry, 2018, https://www.statista.com/study/12481/uscement-industry-statista-dossier/.

[2] C. Meyer, "Concrete materials and sustainable development in the USA," Structural Engineering International, vol. 14, no. 3, pp. 203-207, 2004.
[3] A. A. Almusallam, "Effect of degree of corrosion on the properties of reinforcing steel bars," Construction and Building Materials, vol. 15, no. 8, pp. 361-368, 2001.

[4] J. G. Cabrera, "Deterioration of concrete due to reinforcement steel corrosion," Cement \& Concrete Composites, vol. 18, no. 1, pp. 47-59, 1996.

[5] C. M. Sayers and A. Dahlin, "Propagation of ultrasound through hydrating cement pastes at early times," Advanced Cement Based Materials, vol. 1, no. 1, pp. 12-21, 1993.

[6] P. Mondal, S. P. Shah, and L. Marks, "A reliable technique to determine the local mechanical properties at the nanoscale for cementitious materials," Cement and Concrete Research, vol. 37, no. 10, pp. 1440-1444, 2007.

[7] D. Benavente, M. A. García del Cura, R. Fort, and S. Ordóñez, "Durability estimation of porous building stones from pore structure and strength," Engineering Geology, vol. 74, no. 1-2, pp. 113-127, 2004.

[8] V. M. Malhotra and N. J. E. Carino, Handbook of Nondestructive Testing of Concrete, CRC Press, Boca Raton, FL, USA, 2nd edition, 2004.

[9] J. H. Bungey and S. G. Millard, Testing of Concrete in Structures, Blackie Academic \& Professional Bishopbriggs, Glasgow, UK, 3rd edition, 1996.

[10] T. Juliano, J. N. Meegoda, and D. Watts, "Acoustic emission leak detection on a metal pipeline buried in sandy soil," Journal of Pipeline Systems Engineering and Practice, vol. 4, no. 3, pp. 149-155, 2013.

[11] J. N. Meegoda, J. H. Batagoda, and S. Aluthgun-Hewage, "In situ decontamination of sediments using ozone nano-bubbles and ultrasound," ICE Journal of Environmental Engineering and Science, vol. 12, no. 1, pp. 1-3, 2017.

[12] R. Jones, "The non-destructive testing of concrete," Magazine of Concrete Research, vol. 1, no. 2, pp. 67-78, 1949.

[13] S. Popovics and J. S. Popovics, "A critique of the pulse velocity method for testing concrete," in Proceedings of Nondestructive Evaluation of Civil Structures and Materials Conference, Boulder, CO, USA, October 1990.

[14] L. Wei-Du, "Frequency spectrum analysis of ultrasound testing signal in concrete," in Proceedings of Nondestructive Testing of Concrete Elements and Structures, San Antonio, TX, USA, April 1992.

[15] E. Guillon, F. Benboudjema, and M. Moranville, "Modelling the mechanical evolution of a chemically degraded cement paste at the microstructure scale," in Proceedings of FramCos-5-5th International Conference on Fracture Mechanics of Concrete and Concrete Structures, Vail, CO, USA, April 2004.

[16] K. Velez, S. Maximilien, D. Damidot, G. Fantozzi, and F. Sorrentino, "Determination by nano-indentation of elastic modulus and hardness of pure constituents of Portland cement clinker," Cement and Concrete Research, vol. 31, no. 4, pp. 555-561, 2001.

[17] H. Jeong, K. Hsu, E. S. Robert, and P. K. Liaw, "Characterization of anisotropie elastic constants of silicon-carbide participate reinforced aluminum metal matrix composites: Part II. Theory," Metallurgical and Materials Transactions A, vol. 25, no. 4, pp. 811-819, 1994.

[18] D. P. Mukherjee and S. Pal, "Advances in pattern recognition,” Pattern Recognition Letters, vol. 26, no. 4, pp. 395-398, 2005.

[19] S. Maalej, Z. Lafhaj, and M. Bouassida, "Micromechanical modelling of dry and saturated cement paste: porosity assessment using ultrasonic waves," Mechanics Research Communications, vol. 51, pp. 8-14, 2013. 
[20] F. Eggers and U. Kaatze, "Broad-band ultrasonic measurement techniques for liquids," Measurement Science \& Technology, vol. 7, no. 1, pp. 1-19, 1996.

[21] S. Maalej, Micromechanical Model: Correlation between Hydraulic and Acoustic Parameters of Cement-Based Materials Ph.D. dissertation, 2011, https://tel.archivesuvertes.fr/tel00590429.

[22] R. D. Cook, D. S. Malkus, and P. E. Plesha, Concepts and Applications of Finite Element Analysis, John Wiley \& Sons, Hoboken, NJ, USA, 1989.

[23] D. P. Bentz, "Three-dimensional computer simulation of Portland cement hydration and microstructure development," Journal of the American Ceramic Society, vol. 80, no. 1, pp. 3-21, 1997.

[24] O. Pierard, C. González, J. Segurado, J. L. Lorca, and I. Doghri, "Micromechanics of elasto-plastic materials reinforced with ellipsoidal inclusions," International Journal of Solids and Structures, vol. 44, no. 21, pp. 6945-6962, 2007.

[25] M. G. Hernández, J. J. Anaya, M. A. G. Izquierdo, and L. G. Ullate, "Application of micromechanics to the characterization of mortar by ultrasound," Ultrasonics, vol. 40, no. 1-8, pp. 217-221, 2002.

[26] Z. Hashin, "The elastic moduli of heterogeneous materials," Journal of Applied Mechanics, vol. 29, pp. 143-150, 1960.

[27] Z. Hashinand and S. Shtrikman, "A variational approach to the theory of the elastic behaviour of multiphase materials," Journal of the Mechanics and Physics of Solids, vol. 11, no. 2, pp. 127-140, 1963.

[28] L. J. Walpole, "On bounds for the overall elastic moduli of inhomogeneous systems-I," Journal of the Mechanics and Physics of Solids, vol. 14, no. 3, pp. 151-162, 1966.

[29] M. Eric, "HSFLD241/242: modeling enclosed liquids," 2011, http://www.padtinc.com/blog/the-focus/hsfld241242-modelingenclosed-liquids.

[30] F. Soltani, Caractérisation de la Pâte de Ciment par des Méthodes Ultrasonores, Ph.D. dissertation, ECL, Lille, France, 2010.

[31] J. Paiboon, D. V. Griffiths, J. Huang, and G. A. Fenton, "Numerical analysis of effective elastic properties of geomaterials containing voids using 3D random fields and finite elements," International Journal of Solids and Structures, vol. 50, no. 20-21, pp. 3233-3241, 2013. 


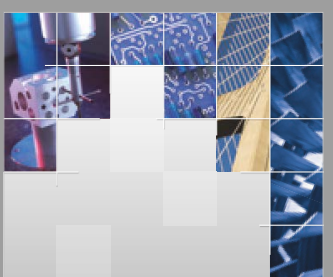

\section{Enfincering}
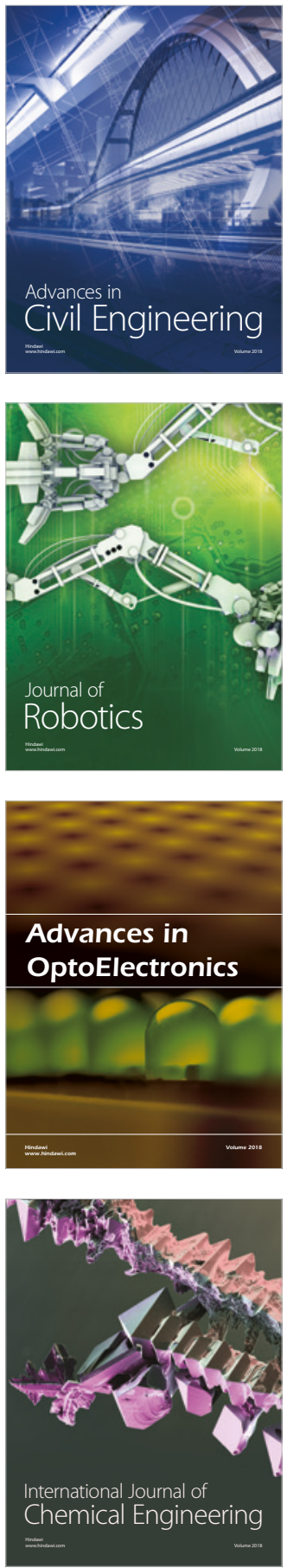

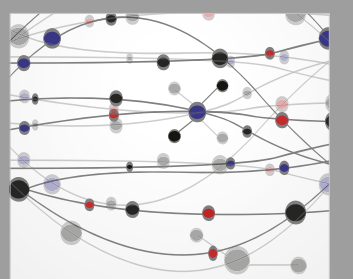

\section{Rotating \\ Machinery}

The Scientific World Journal

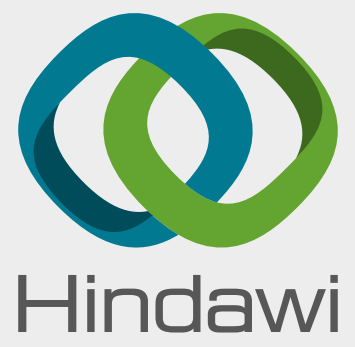

Submit your manuscripts at

www.hindawi.com
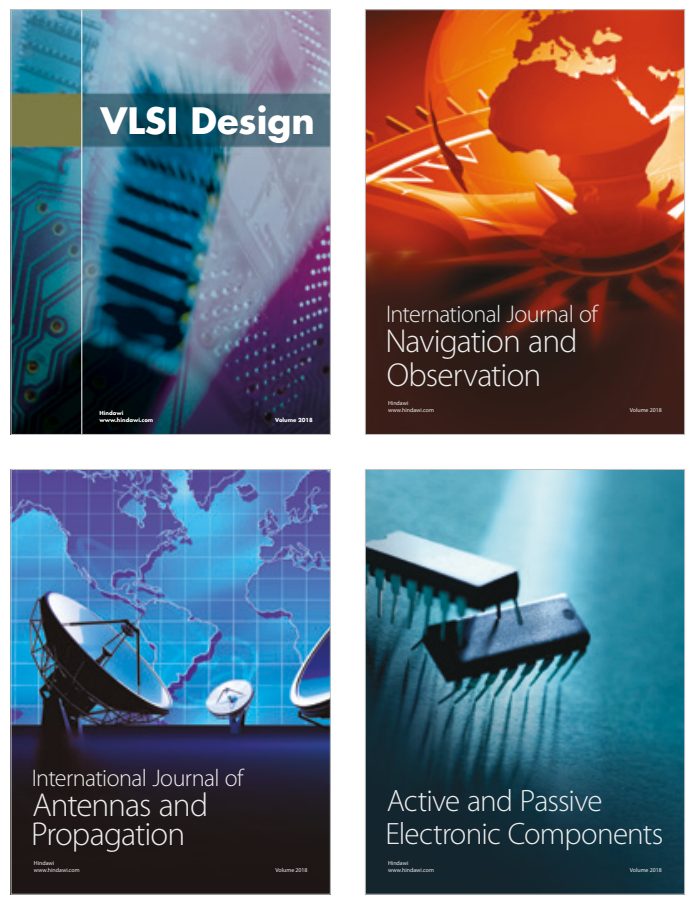
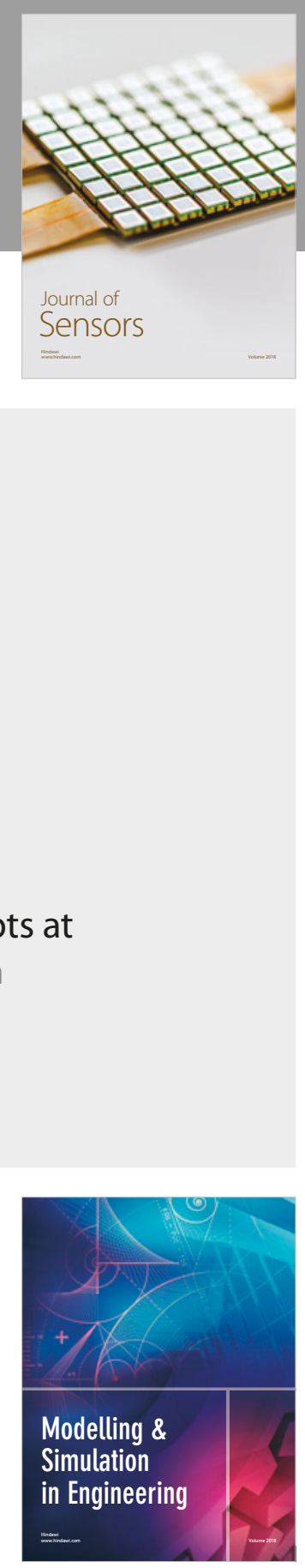

\section{Advances \\ Multimedia}
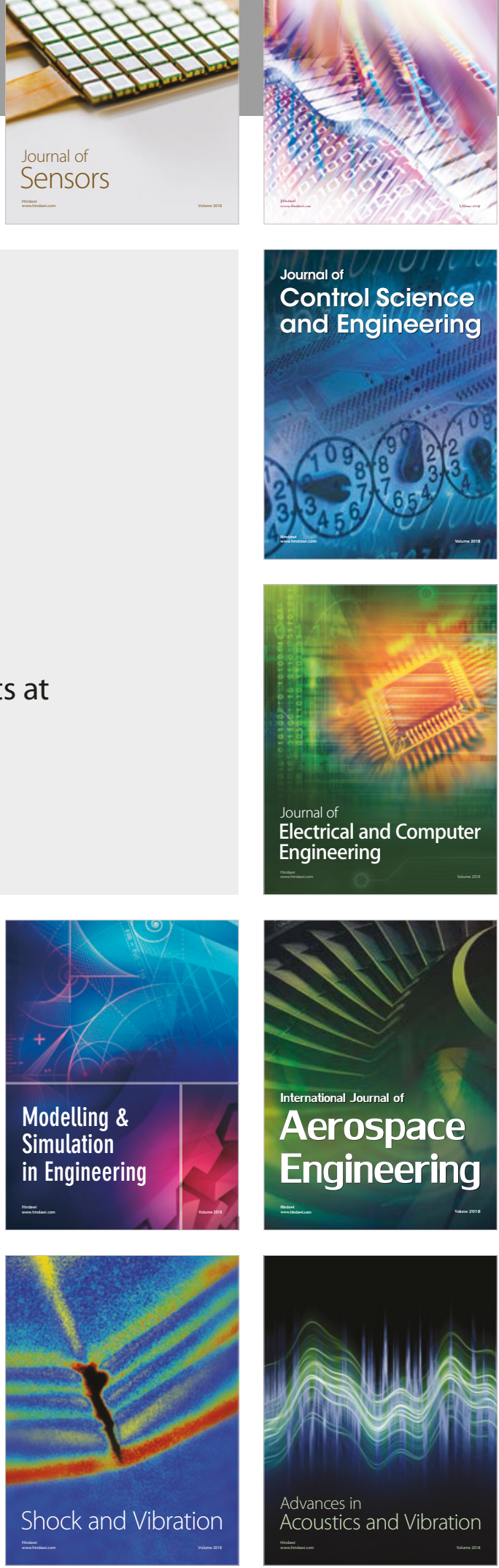